\title{
EUROPEAN ROUND ROBIN TEST ON SOLAR COLLECTORS AND SOLAR THERMAL SYSTEMS
}

\author{
Stephan Fischer ${ }^{1}$, Maria João Carvalho ${ }^{2}$, Christian Weißmüller ${ }^{3}$ \\ Institute for Thermodynamics and Thermal Engineering (ITW), \\ Research and Testing Centre for Thermal Solar Systems (TZS), \\ University Stuttgart, Pfaffenwaldring 6, 70550 Stuttgart, Germany \\ Phone: +49 (0)71168563231 \\ Fax: $+49(0) 71168563242$ \\ E-Mail: fischer@itw.uni-stuttgart.de \\ Maria João Carvalho, LNEG - Laboratório Nacional de Energia e Geologia ${ }^{2}$, Portugal \\ Christian Weißmüller, Institut für Eignungsprüfung (IfEP) ${ }^{3}$, Germany \\ Franz Helminger, AIT Austrian Institute of Technology (AIT), Austria \\ Alberto García de Jalón, Centro Nacional de Energías Renovables (CENER), Spain \\ Dominique Caccavelli, Centre Scientifique et Technique du Bâtiment (CSTB), France \\ Emmanouil Mathioulakis, Solar \& other Energy Systems Laboratory (NCSR "DEMOKRITOS"), Greece \\ Korbinian Kramer, Fraunhofer ISE, Germany \\ Carsten Lampe, Institut für Solarenergieforschung Hameln (ISFH), Germany \\ Pilar Navarro Rivero, Instituto Tecnológico de Canarias (ITC), Spain \\ Danjana Theis, IZES gGmbH - Institut für ZukunftsEnergieSysteme, Germany \\ Peter Kovacs, SP Technical Research Institute of Sweden, Sweden \\ Ulrich Fritzsche, TÜV Rheinland Energie und Umwelt GmbH, Germany
}

\section{Introduction}

Within the European project QAiST (Quality Assurance in Solar Thermal Heating and Cooling Technology) a Round Robin test on solar collectors and solar thermal systems is carried out in the years 2010 and 2011. For two different collector types, one flat plate collector and one evacuated tubular collector with CPC reflector, thermal performance tests according to EN 12975-2 (EN 12975, 2006) are carried out by 12 different test institutes throughout Europe. The two different solar thermal systems, one thermosiphon system and one system with forced circulation are subject to a thermal performance test according to EN 12976-2 (EN 12976, 2006) and are tested by 9 different test institutes.

In order to finish the Round Robin test within two years despite of the high number of participants, the following procedure was applied: Each participant received in the year 2010 samples of the two different collector types and of the two solar thermal system types respectively. After testing, the samples have been sent to the next test institute to be tested within the year 2011. Thus all institutes are testing identical collectors and system types taken out of the same production batch, however each unique collector or system is only tested by two institutes.

For the first time Round Robin tests on solar thermal products are evaluated by an independent institute (Institut für Eignungsprüfung) using the acknowledged procedures for the evaluation of proficiency tests.

This paper presents some of the midterm results of the Round Robin test in an anonymous and standardised way.

\section{Statistical design}

The statistical design for proficiency testing is based on ISO 13528 (2005) and ISO/IEC 17043 (2010). The deviation of laboratory's mean $M V_{L A B}$ value from the assigned value $X$ was evaluated. 


\subsection{Determination of assigned value}

The assigned value $X$ is determined as a consensus value of the results of all participating laboratories. It is calculated as a robust mean value (see figure 1). For each test parameter an assigned value was calculated. The respective assigned value $X$ is the median of all laboratories results $M V_{L A B}$.

The normalised inter-quartile range $n_{I Q R}$ is used as standard deviation for the proficiency assessment $\sigma\left(n_{I Q R}\right)$ :

$n_{I Q R}=0,7413(Q 3-Q 1) \quad$ (eq. 1)

$75 \%$ of all values are lower than Q3, $25 \%$ of all values are lower than Q1. (Q3-Q1) is called inter-quartile range (IQR). Figure 1 graphically presents the (IQR). The factor 0.7413 derives from the standard normal distribution, which has a mean of zero and a standard deviation equal to one. The width of the inter quartile range of such a distribution is 1.34898 and results to $1 / 1.34898=0.7413$. Multiplying IQR by this factor makes it comparable to a standard deviation (PTPM 1.1, 2008).

The results of proficiency tests are assessed with the help of a Z-score that is calculated for each laboratory and each test parameter according to equation 2 :

$Z=\frac{M V_{L A B}-X}{\sigma\left(n_{I Q R}\right)}$

According to ISO/IEC 17043 (2010) the following judgements are made:

$|\mathrm{Z}| \leq 2$ satisfactory participated

$|\mathrm{Z}| \geq 3$ unsatisfactory participated

$2<|Z|<3$ result questionable.

Figure 1 presents an example for the statistical evaluation as presented above.

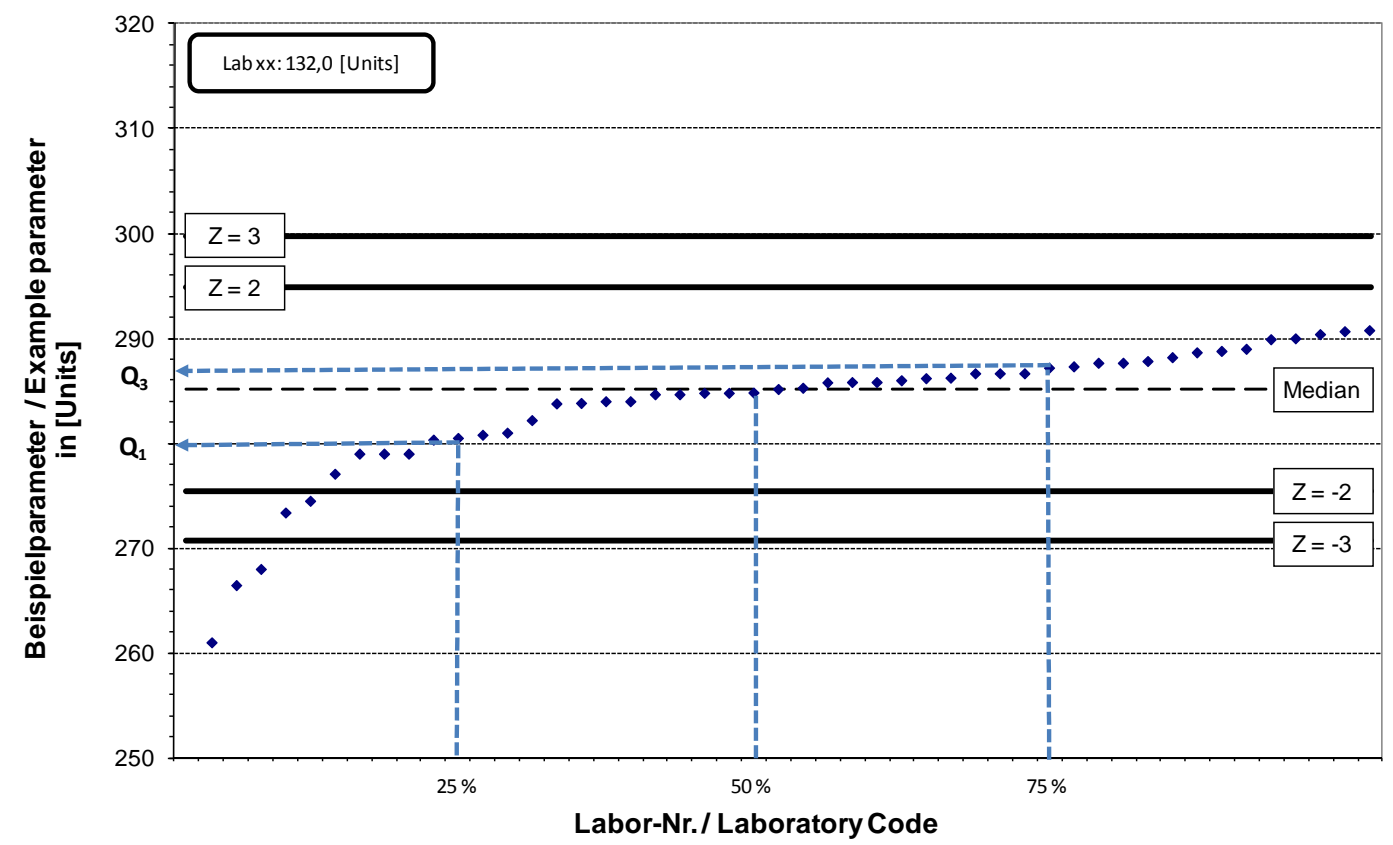

Fig. 1: Example of the statistical evaluation

In the special case of the QAiST project the evaluation for the intermediate report had to be adopted to ensure an independent testing in round 1 and 2 . Therefore the results were only displayed using the resulting Z-scores. The standard deviation of each parameter (in percent) was displayed to give all participants a first look on the result without publishing the assigned value. Additionally more than one parameter could be summarised in one drawing. Examples are presented in section 3. 


\section{Round Robin test collectors}

During the last 10 years two Round Robin collector tests have been carried out on European level with more than 5 participants. The first was carried out on two identical flat plate collectors by 7 test laboratories from Austria, Germany and Switzerland in the years 2003 and 2004 (Fischer et. al., 2005). The second and latest was carried out during the years 2007 and 2008, with participants from Austria, France, Germany, Greece, Portugal, Spain and Sweden (Fischer et. al., 2008). Subject of comparison have been two identical flat plate collectors and one evacuated tubular collector.

This Round Robin constitutes the first comparison of test results involving 12 laboratories with the main objective of evaluation of laboratory proficiency in performance testing of solar collectors.

\subsection{Test samples and procedure}

\section{Test samples}

Subject of the Round Robin tests are:

- A flat plate collector with copper absorber, polymeric frame and a standard glass cover. The absorber strips are coated with black chrome and are fixed to the fluid channels by ultrasonic welding.

- An evacuated tubular collector (Sydney type) with CPC reflector. The heat from the absorber is transferred by an aluminum heat transfer sheet to the U-pipe which is passed through by the heat transfer fluid.

Altogether 13 test samples of each collector type have been sampled from the production line by independent inspectors. All major components of the collector like the glass cover, absorber, reflector and evacuated tubes were taken from the same batch to ensure the maximum compatibility of the picked test sample to each other.

Preconditioning of test samples

Before testing the empty collectors were exposed to at least $5 \mathrm{~h}$, but not more than $10 \mathrm{~h}$ of irradiance of more than $700 \mathrm{~W} / \mathrm{m}^{2}$. Ambient temperature and radiation have been monitored and reported.

\section{Cleaning during testing}

When outdoor testing was carried out the collector has been cleaned every morning.

\section{Test methods}

All test methods according to EN 12975-2:2006, section 6 could be applied by the participants. Collector parameters to be determined are: $\eta_{0}, a_{1}, a_{2}, c_{\text {eff }}$ and the incident angle modifiers.

\section{Test methods}

Flat plate collector: In case the steady state method (section 6.1) is used the incidence angle modifier $\mathrm{K}(\theta)$ has to be determined for an angle of incident of $50^{\circ}$, in case of the quasi-dynamic method (section 6.3) the collector parameter $b_{0}$ has to be determined and the values (beam and global) for $50^{\circ}$ have to be calculated.

Evacuated tubular collector: In all cases the incidence angle modifier $\mathrm{K}(\theta)$ has to be determined for angles of incident of $30^{\circ}, 40^{\circ}, 50^{\circ}$ and $60^{\circ}$ in transversal direction and $50^{\circ}$ in longitudinal direction.

The following sections present selected results at midterm of the Round Robin test.

\subsection{Presentation of selected results}

To not interfere with the ongoing Round Robin test only some results are presented using the Z-score without presenting values of the corresponding collector parameter.

Figure 2 shows as example the Z-score of the determined aperture area of the evacuated tubular collector. The $\mathrm{x}$-coordinate from 1 to 11 represent the different measurements of the eleven laboratories which turned in a report sheet. All participants are well between the \pm 2 -threshold representing satisfactory participation. The standard deviation of all measurements is $0.5 \%$. 


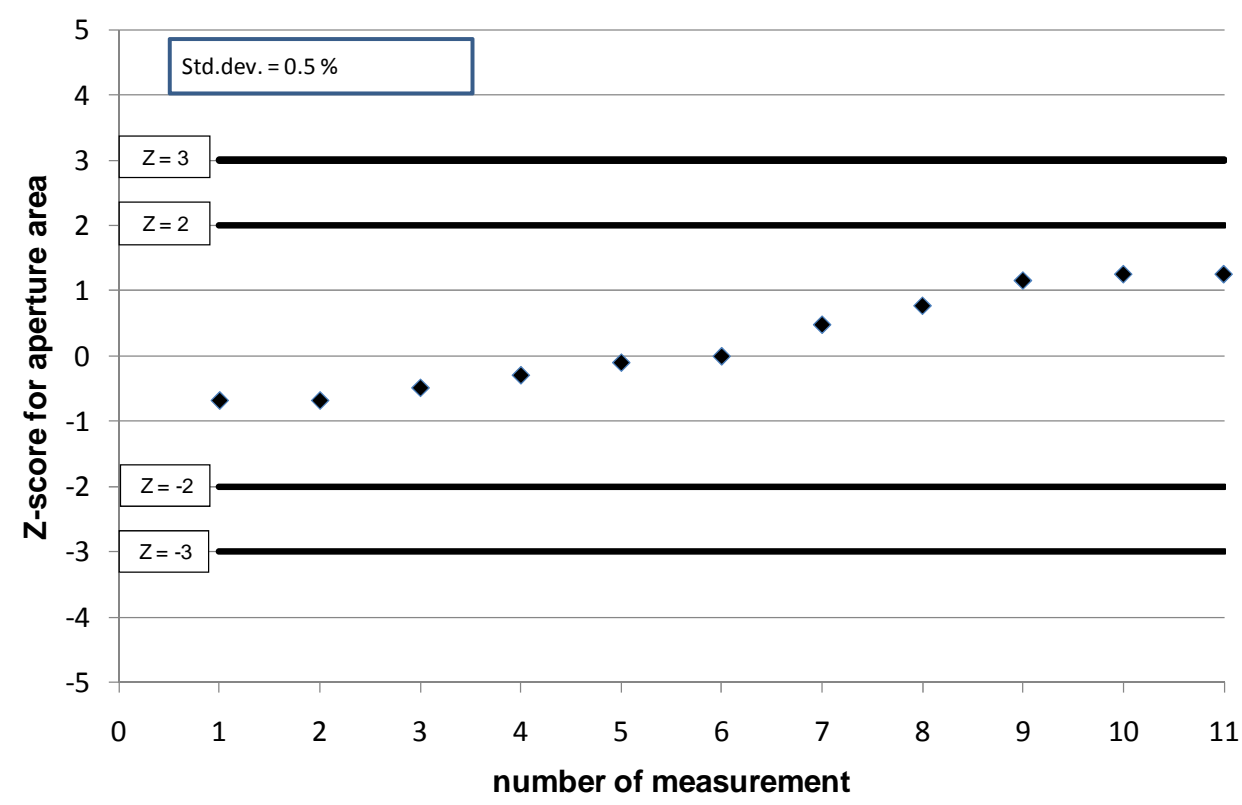

Fig. 2: Z-scores of all measurements of the aperture area of the evacuated tubular collector

Figure 3 and 4 show the Z-score of the collector output of the flat plate collector and the evacuated tubular collector for a hemispherical irradiance of $1000 \mathrm{~W} \mathrm{~m}^{-2}$. The values are calculated according to EN 12975:2006 from the collector parameter $\eta_{0}, a_{1}, a_{2}$ derived during the performance test of the collectors. The different symbols represent the different temperature difference between the mean fluid temperature and ambient temperature $\left(\vartheta_{\mathrm{fl}, \mathrm{m}}-\vartheta_{\mathrm{amb}}=0 \mathrm{~K}, 10 \mathrm{~K}, 30 \mathrm{~K}\right.$ and $\left.50 \mathrm{~K}\right)$.

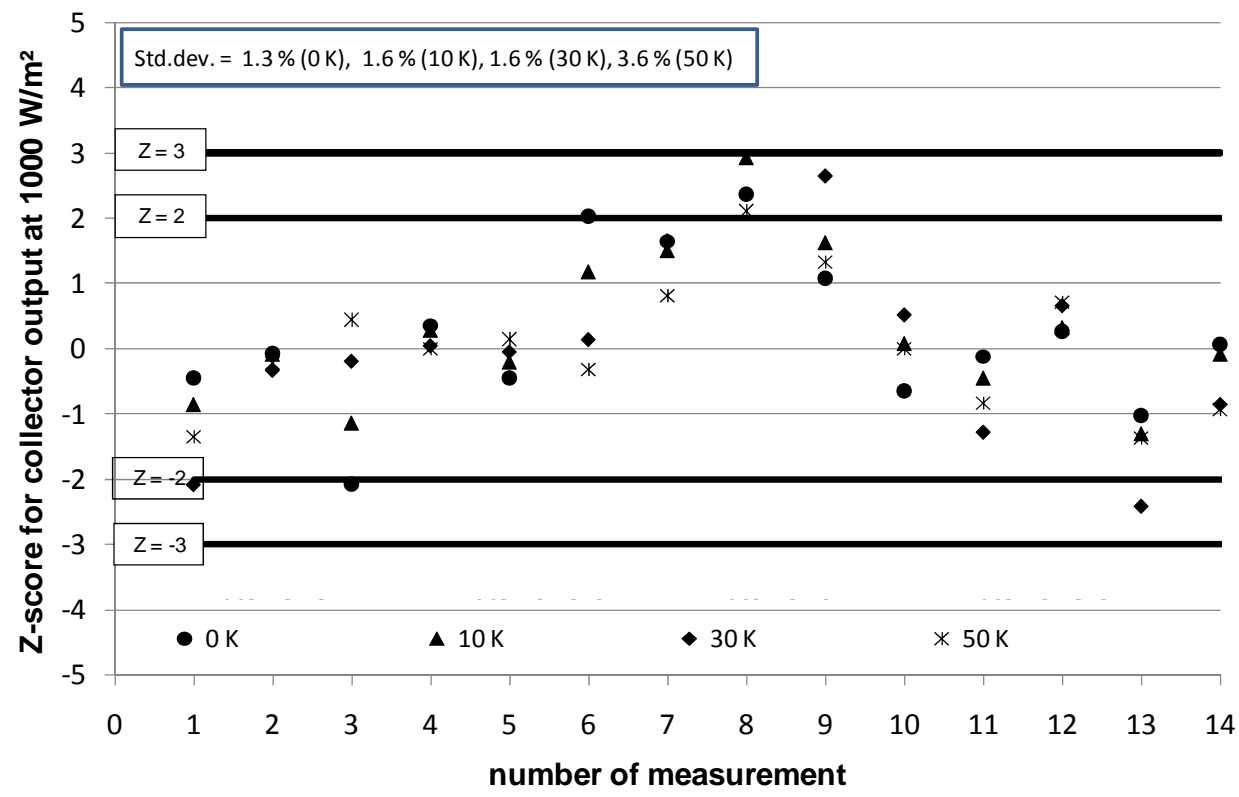

Fig. 3: Z-scores of all measurements of the collector output at $1000 \mathrm{~W} \mathrm{~m}^{-2}$ for the flat plate collector

The $\mathrm{x}$-coordinate of figure 3 shows 14 values because one test laboratory handed in 3 different results for evaluation to IfEP. Except for measurement 8 the majority of the Z-scores are well between the \pm 2 -threshold representing satisfactory participation. The result was classified by IfEP as very good.

An even slightly better result shows figure 4 representing the Z-scores for the same collector output of the evacuated tubular collector. Only measurement no. 10 is rated as questionable, nevertheless again IfEP classifies the overall results as very good. 


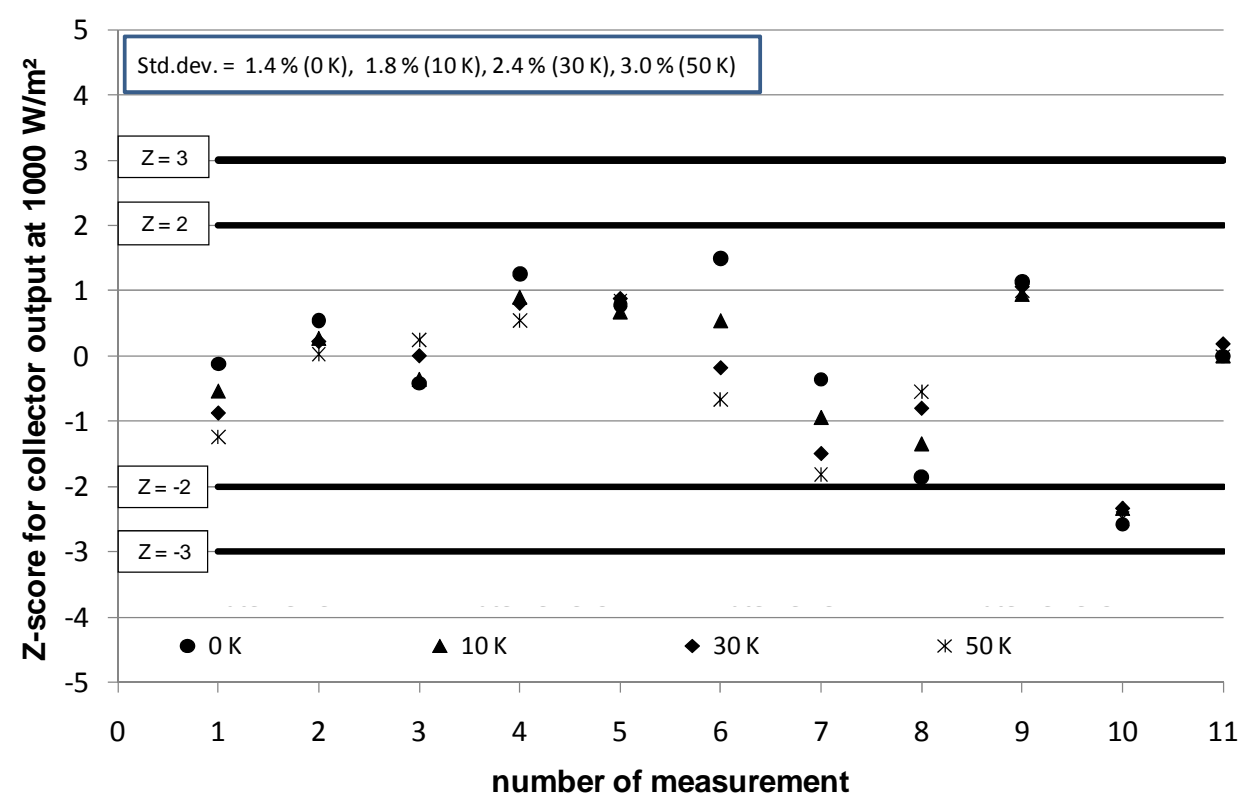

Fig. 4: Z-scores of all measurements of the collector output at $1000 \mathrm{~W} \mathrm{~m}^{-2}$ for the evacuated tubular collector

To present a more familiar picture of the results the power curves for all measurements are presented in figure 5 and 6 . The power curves have been calculated from the Z-scores shown in figures 3 and 4 using arbitrarily values of $\eta_{0}, a_{1}, a_{2}$ to not interfere with the ongoing Round Robin test. The black curves displayed represent the error bands calculated for a $95 \%$ confidence interval according to GUM, 1995. Although the power curves show a deviation of \pm 2 percentage points all derived power curves are within the error bands.

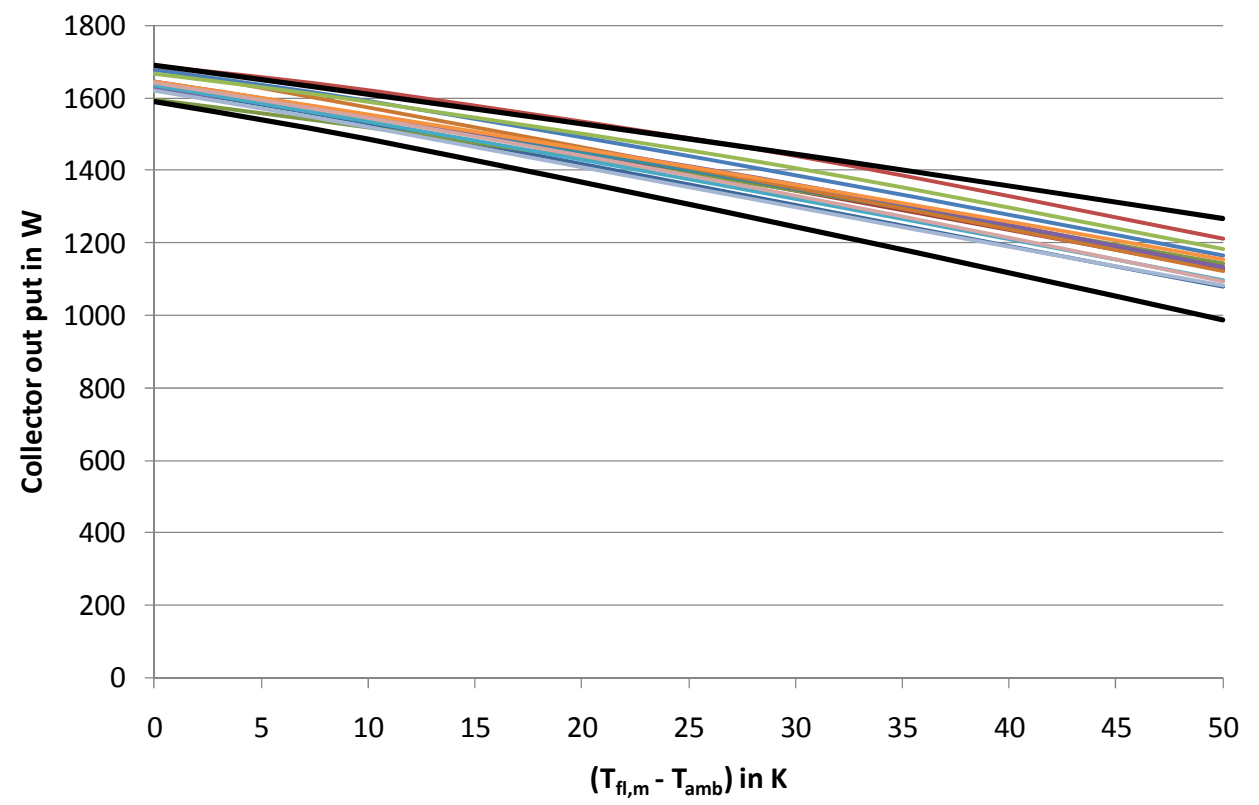

Fig. 5: Power curves and error bands (95 \% confidence interval) for the measurements of the flat plate collector 


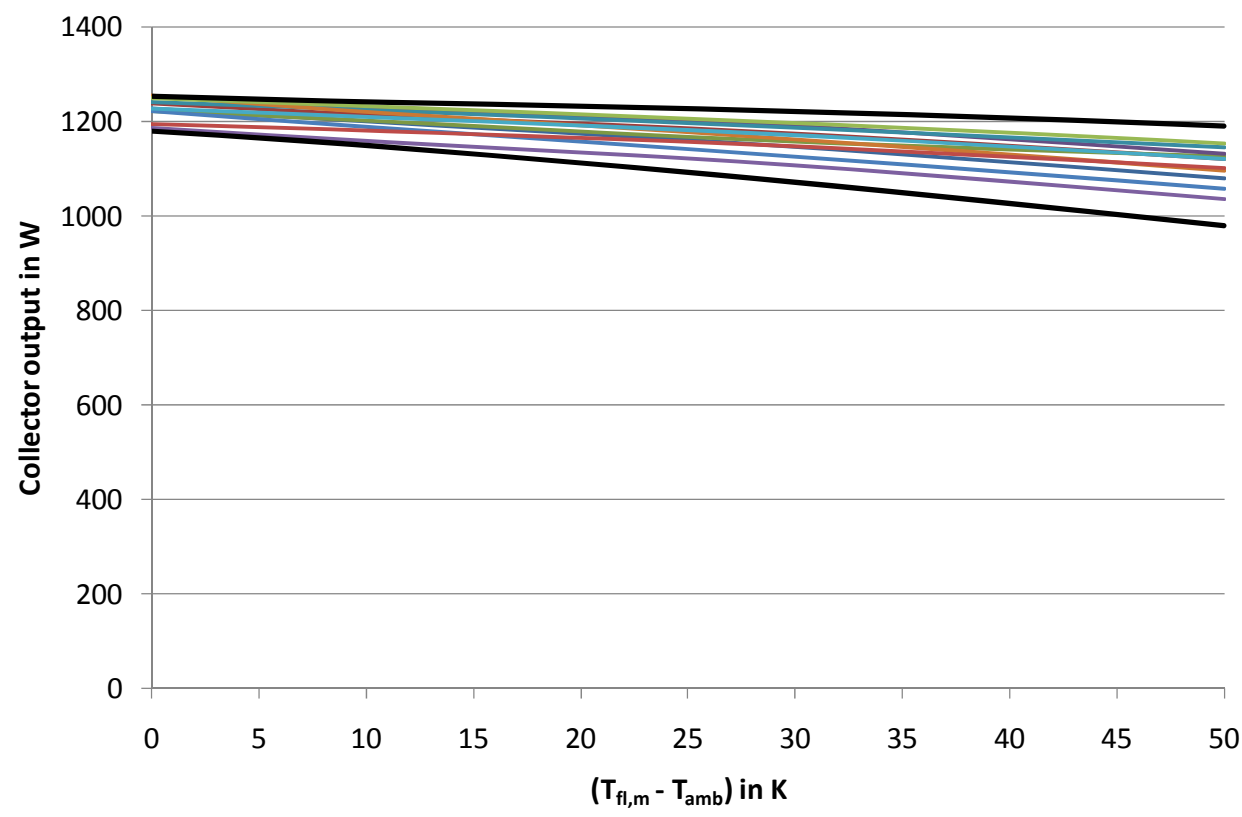

Fig. 6: Power curves and error bands (95 \% confidence interval) for the measurements of the evacuated tubular collector

At midterm of the ongoing collector Round Robin test the Institut für Eignungsprüfung (IfEP) attested the participants a very good outcome compared to other proficiency tests so far.

\section{Round Robin test systems}

Collector and Systems Testing Group (CSTG), whose activities were co-ordinated by the Joint Research Centre of Ispra (Aranovitch et al., 1989), developed a test method - CSTG test method - which is now described in ISO 9459-2:1995. This work included round robin tests of different systems for validation of the test method. Analyses of these tests and of its validation can be seen in reference (Bourges et al., 1991).

In the frame of the European Programme, SM\&T (Standards, Measurements and Testing), the project "Bridging the gap: Research and experimental validation on the DST performance test method for solar domestic water heaters" (Naron, 1999), had as its main objective the validation of the DST test method (ISO 9459-5). In this project several European test laboratories tested different types of Factory Made Systems. Analyses of the comparison between DST and CSTG tests can be seen in reference (M.J. Carvalho and D. Naron, 2001).

This Round Robin constitutes the first comparison of test results involving a large number of laboratories with the main objective of evaluation of laboratory proficiency in testing of Factory Made Systems.

\subsection{Initial conditions for testing}

The main characteristics of the two types of systems tested are described in Table 1.

Table 1 - Characteristics of systems tested.

\begin{tabular}{|l|c|c|}
\hline & Thermosyphon System & Forced Circulation System \\
\hline Number of collectors & 1 & 3 \\
\hline Collector Aperture Area & $1.87 \mathrm{~m}^{2}$ & $2.35 \mathrm{~m}^{2}$ \\
\hline Store Volume & 1801 & 4001 \\
\hline Collector loop Heat Exchanger & Jacket & Coil on bottom of storage tank. \\
\hline Type of Auxiliary & Not Applicable & $\begin{array}{c}\text { External with coil on upper part of the } \\
\text { storage tank as heat exchanger. }\end{array}$ \\
\hline
\end{tabular}


Before testing the participating laboratories agreed on the following conditions for the tests:

- Mounting of the systems made by the laboratory, following carefully the instructions from the manufacturer; the same instructions followed on the first (2010) and second (2011) mounting of the system; The heat transfer fluid: $100 \%$ water;

- Test methodologies for thermal performance determination: Chosen by each laboratory according to Table 2 of EN 12976-2:2006;

- Presentation of results: According to Annex B of EN 12976-2, the thermal performance indicators are calculated for four locations (Athens, Davos, Stockholm and Wuerzburg) and for five load volumes (different load volumes depending on the store volume).

- $\quad$ Thermosyphon system (180 1 storage tank): 140, 170, 200, 250, 3001

- $\quad$ Forced circulation system (400 l storage tank): 200, 250, 300, 400, 6001

\subsection{Preliminary results.}

The results of 2010 show that all laboratories used Dynamic System Testing Method according to ISO 94595:2007 for testing of both, thermosyphon and forced circulation systems. All laboratories reported the full set of parameters of DST test, according to Table 2.

Table 2 - DST parameters.

\begin{tabular}{|l|c|l|}
\hline Parameter & Symbol & Unit \\
\hline Effective collector area & $\mathrm{Ac}^{*}$ & $\mathrm{~m}^{2}$ \\
\hline Effective collector loss coefficient & $\mathrm{uc}^{*}$ & $\mathrm{~W} \mathrm{~m}^{-2} \mathrm{~K}^{-1}$ \\
\hline Total store heat loss coefficient & $\mathrm{Us}$ & $\mathrm{W} \mathrm{K}^{-1}$ \\
\hline Total store heat capacity & $\mathrm{Cs}$ & $\mathrm{MJ} \mathrm{K}^{-1}$ \\
\hline Mixing constant & $\mathrm{DL}$ & \\
\hline Store stratification & $\mathrm{Sc}$ & \\
\hline $\begin{array}{l}\text { Fraction of the store heated by the } \\
\text { auxiliary heater }\end{array}$ & $\mathrm{f}_{\mathrm{aux}}$ & $\%$ \\
\hline
\end{tabular}

${ }^{1}$ Only for solar plus supplementary systems.

The analysis of Z-score (see section 2. for definition) was applied to all parameters (except $f_{\text {aux }}$ ) and it is possible to conclude that almost all laboratories obtained a Z-score lower than 2 (Satisfactory results) for all parameters, as can be seen in Table 3 .

Table 3 - Number of Laboratories with Z-score within stated intervals (thermosyphon system (solar only system) / forced circulation system).

\begin{tabular}{|c|c|c|c|c|c|c|}
\hline & $\mathrm{Ac}^{*}$ & $\mathrm{uc}^{*}$ & $\mathrm{Us}$ & $\mathrm{Cs}$ & $\mathrm{DL}$ & $\mathrm{Sc}$ \\
\hline $\begin{array}{c}-2<\mathrm{Z}<2 \\
\text { Satisfactory }\end{array}$ & $7 / 8$ & $8 / 9$ & $8 / 9$ & $8 / 7$ & $6 / 8$ & $6 / 8$ \\
\hline $\begin{array}{c}-3<\mathrm{Z}<-2 \text { and } 2<\mathrm{Z}<3 \\
\text { Questionable }\end{array}$ & $1 / 0$ & $0 / 0$ & $1 / 0$ & $1 / 0$ & $2 / 0$ & $1 / 0$ \\
\hline $\begin{array}{c}\mathrm{Z}<-3 \text { and } \mathrm{Z}>3 \\
\text { Unsatisfactory }\end{array}$ & $1 / 1$ & $1 / 1$ & $0 / 0$ & $0 / 2$ & $1 / 1$ & $2 / 1$ \\
\hline
\end{tabular}

The results presented for the forced circulation system are not final results since the evaluation was made not separating the system when tested as solar only system (6 laboratories presented these results) and when tested as solar plus supplementary system (4 laboratories presented these results).

The indicator considered to compare results of Long Term Performance Prediction is $f_{\text {sol }}$. Although the standard deviation in each parameter is high, the results of Long Term Performance Prediction (LTPP) for the thermosyphon system show standard deviations lower than 10\% (see Table 4). Almost all laboratories 
obtained a Z-score lower then 2 (satisfactory results) for all load volumes, as can be seen in Table 5 .

Table 4 - Standard deviation (\%) for thermosyphon system results.

\begin{tabular}{|c|c|c|c|c|}
\hline $\begin{array}{c}\text { Vload } \\
{[\text { liter] }}\end{array}$ & Stockhom & Wuerzburg & Davos & Athens \\
\hline 140 & 6.2 & 5.2 & 5.0 & 2.7 \\
\hline 170 & 6.4 & 5.0 & 6.5 & 3.1 \\
\hline 200 & 7.3 & 9.6 & 9.1 & 1.8 \\
\hline 250 & 5.6 & 7.1 & 8.4 & 5.3 \\
\hline 300 & 5.7 & 6.0 & 7.6 & 6.6 \\
\hline
\end{tabular}

Table 5 - Number of Laboratories (Satisfactory/questionable/Unsatisfactory)

\begin{tabular}{|c|c|c|c|c|}
\hline $\begin{array}{c}\text { Vload } \\
{[\text { liter] }}\end{array}$ & Stockhom & Wuerzburg & Davos & Athens \\
\hline 140 & $8 / 1 / 0$ & $7 / 2 / 0$ & $6 / 2 / 1$ & $7 / 1 / 1$ \\
\hline 170 & $6 / 2 / 0$ & $6 / 2 / 0$ & $6 / 0 / 2$ & $6 / 1 / 1$ \\
\hline 200 & $8 / 1 / 0$ & $8 / 1 / 0$ & $8 / 1 / 0$ & $8 / 1 / 0$ \\
\hline 250 & $7 / 1 / 1$ & $8 / 0 / 1$ & $8 / 0 / 1$ & $7 / 1 / 1$ \\
\hline 300 & $7 / 1 / 1$ & $7 / 1 / 1$ & $7 / 1 / 1$ & $7 / 1 / 1$ \\
\hline
\end{tabular}

Considering the demand volume of 2001 , the Solar Fraction values obtained are shown in Fig.7. In this figure only the values corresponding to results obtained with Z-score lower than 2 are shown. Lower deviations are shown for Athens when compared with other locations. In general it is reasonable to expect that for locations with higher irradiation, the deviation in the test results is lower.

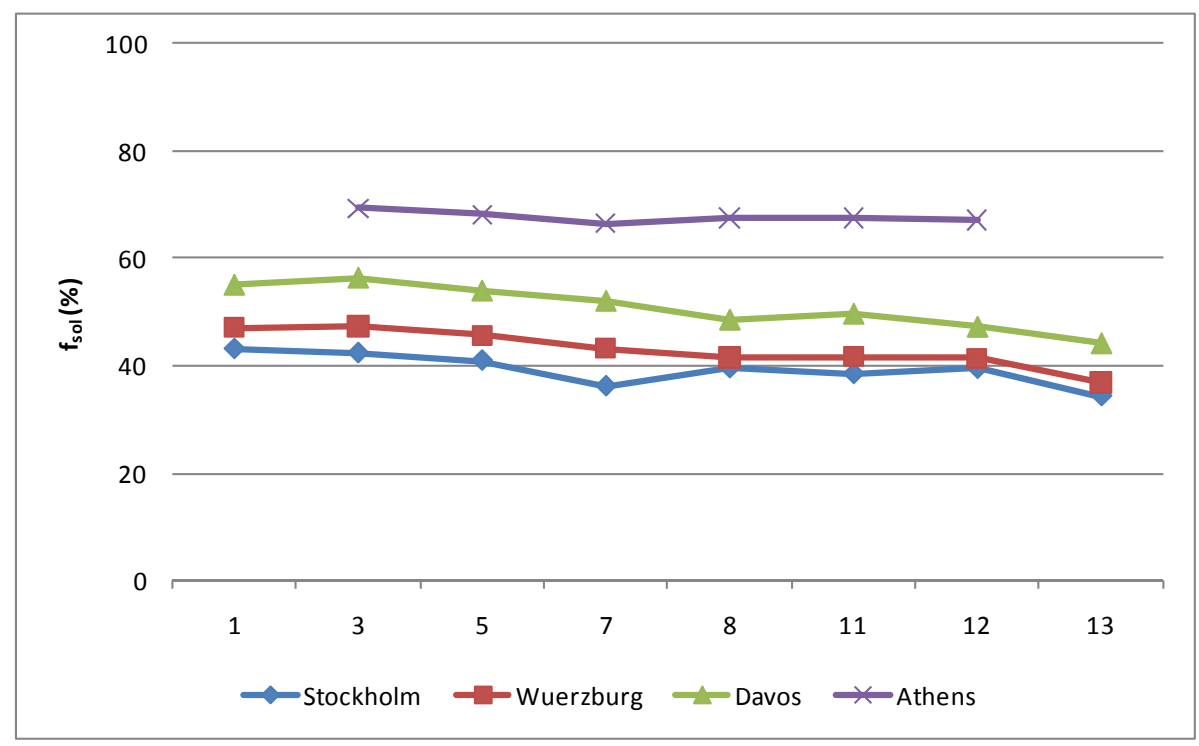

Fig. 7 - $f_{\text {sol }}$ for Thermosyphom System (Vload = 200 l) (only values for $\left.Z<2\right)$

In the case of the forced circulation system it was not possible to do an analysis of the results considering the separation between Solar Only System and Solar Plus Supplementary Systems. The analysis of results made until this moment shows that almost all laboratories obtained a Z-score lower then 2 (satisfactory results) for all load volumes, but with higher standard deviations.

\section{Conclusion and Outlook}

The midterm results of the Round Robin for the collectors can be considered as very good since a majority of laboratories presents "satisfactory" results. All power curves derived from the performance measurements are with the $95 \%$ confidence interval when an uncertainty assessment is carried out according to GUM 
(1995).

The preliminary results of the Round Robin for thermosyphon systems show that results can be considered good since a majority of Laboratories presents "satisfactory" results. It is possible to consider that the uncertainty of the results is within $10 \%$ and this uncertainty covers:

- Differences in testing

- Differences in systems

In the case of the forced circulation system, the analysis of results made until this moment shows that almost all laboratories obtained a Z-score lower then 2 (satisfactory results) for all load volumes, but with higher standard deviations. Clarification on the results presented as Solar Only Systems and Solar Plus Supplementary Systems is still needed.

According to IfEP that evaluated the results of the Round Robin test of collectors and systems the overall results can be classified as very good compared to other proficiency tests.

In September 2011 the second round of the Round Robin test will be completed followed by a final evaluation of all results which will be subject of a further publication.

\section{Nomenclature}

\begin{tabular}{lll}
\hline Symbol & Unit & Quantity \\
\hline$a_{1}$ & $\mathrm{~W} \mathrm{~m}^{-2} \mathrm{~K}^{-1}$ & Heat loss coefficient \\
$a_{2}$ & $\mathrm{~W} \mathrm{~m}^{-2} \mathrm{~K}^{-2}$ & Temperature dependent heat loss coefficient \\
$\mathrm{Ac}^{*}$ & $\mathrm{~m}^{2}$ & Effective collector area \\
$c_{\text {eff }}$ & $\mathrm{J} \mathrm{m}^{-2} \mathrm{~K}$ & Effective collector capacity \\
$\mathrm{Cs}$ & $\mathrm{MJ} \mathrm{K}^{-1}$ & $\begin{array}{l}\text { Total store heat capacity } \\
\text { Mixing constant }\end{array}$ \\
$\mathrm{DL}$ & & Fraction of the store heated by the auxiliary heater \\
$\mathrm{f}_{\text {aux }}$ & $\%$ & Effective collector loss coefficient \\
$\mathrm{uc}$ & $\mathrm{W} \mathrm{m}^{-2} \mathrm{~K}^{-1}$ & Total store heat loss coefficient \\
$\mathrm{Us}$ & $\mathrm{W} \mathrm{K}^{-1}$ & Store stratification \\
$\mathrm{Sc}$ & & Conversion factor \\
$\eta_{0}$ & & Ambient temperature \\
$\vartheta_{\text {amb }}$ & ${ }^{\circ} \mathrm{C}$ & Mean fluid temperature \\
$\vartheta_{f l, m}$ & ${ }^{\circ} \mathrm{C}$ & Incidence angle modifier \\
$K(\theta)$ & & Incident angle of the beam irradiance \\
$\theta$ & $\circ$ &
\end{tabular}

\section{References}

Aranovitch, E., D. Gilliaer, W.B. Gillett, J.E.Bates (Ed.), 1989. Recommendations for performance and durability tests of Solar Collectors and Water Heating Systems (Part A).

Bourges B., Rabl A., Leide B., Carvalho M.J., Collares Pereira M., 1991. Accuracy of the European solar water heater test procedure. Part 1: Measurement errors and parameter estimates. Part 2: Prediction of longterm performance. Solar Energy 47, 1-25

Carvalho, M.J., D.J. Naron, 2000. Comparison of test methods for evaluation of thermal performance of preheat and solar-only factory made systems, Solar Energy, Vol 69 (suppl.), pág. 145-156

EN 12975, 2006: EN 12975-2:2006. Thermal Solar Systems and Components - Solar Collectors - Part 2:

Test Methods.

EN 12976, 2006: EN 12976-2:2006. Thermal solar systems and components - Factory made systems - Part 2:

Test methods 
Fischer, S., et. al., 2005. "Round-Robin" Test of a Solar Thermal Collector, Proceedings $2^{\text {nd }}$ European Solar Thermal Energy Conference.

Fischer, S., et. al., 2008. Collector Intercomparison Test within the Solar Keymark II Project, Presentation during the EUROSUN 2008 conference, Lisbon.

GUM, 1995. Guide to the expression of uncertainty in measurement, International Organisation of Standardisation, Switzerland.

ISO 9459.2 (1995) Solar heating - Domestic water heating systems - Part 2: Outdoor test methods for system performance characterisation and yearly performance prediction of solar only systems

ISO 9459-5:2007. Solar heating - Domestic water heating systems - Part 5: System Performance characterisation by means of whole-system tests and computer simulation

ISO 13528:2005. Statistical methods for use in proficiency testing by interlaboratory comparisons. International Organisation for Standardization, Genève, September 2005.

ISO/IEC 17043:2010. Conformity assessment - General requirements for proficiency testing. International Organisation for Standardization, Genève, February 2010.

PTPM 1.1. Guide to Proficiency Testing Australia, PTA. Australia, April 2008

Acknowledgement: The work described in this paper is partly funded by European Commission within the Program "Intelligent Energy Europe" under grant number IEE/08/593. The authors gratefully thank for this support and carry the full responsibility of the content of this publication. 